\title{
A Nanoscale Characterization with Electron Microscopy of Multilayered CrAIYN Coatings: A Singular Functional Nanostructure
}

\author{
Teresa C. Rojas, ${ }^{1, \star}$ Santiago Domínguez-Meister, ${ }^{1}$ Marta Brizuela, ${ }^{2}$ Alberto García-Luis, ${ }^{2}$ \\ Asunción Fernández, ${ }^{1}$ and Juan Carlos Sánchez-López ${ }^{1}$ \\ ${ }^{1}$ Instituto de Ciencia de Materiales de Sevilla (CSIC-Univ. Sevilla), Avda. Américo Vespucio 49, 41092-Sevilla, Spain \\ ${ }^{2}$ TECNALIA, Mikeletegui Pasealekua, 20009 Donostia-San Sebastián, Spain
}

\begin{abstract}
A combination of transmission electron microscopy techniques and spatially resolved microanalysis is used to investigate the nanostructure, constituting phases, and chemical elemental distribution in CrAlYN multilayered coatings. The location of the metallic elements and their chemical state are needed to understand their functional properties. Samples were prepared with variable Al (4-12 at $\%)$ and $\mathrm{Y}(2-5$ at $\%)$ contents by direct current reactive magnetron sputtering on silicon substrates using metallic targets and $\mathrm{Ar} / \mathrm{N}_{2}$ mixtures under different deposition parameters (power applied to the target and rotation speed of the sample holder). The changes produced in the nanostructure and chemical distribution were investigated. Nanoscale resolution electron microscopy analysis has shown that these coatings present a singular nanostructure formed by multilayers containing at a certain periodicity nanovoids filled with molecular nitrogen. Spatially resolved energy dispersive spectroscopy and electron energy loss elemental mappings and profiles showed that the chromium, aluminum, and yttrium atoms are distributed in a sequential way following the position of the targets inside the deposition chamber. Analysis of the different atomic distribution and phases formed at the nanoscale is discussed depending on the deposition parameters.
\end{abstract}

Key words: EELS, high angle annular dark field (HAADF), phase composition, sputtering, nanoscale chemical mapping, $\mathrm{N}_{2}$-filled nanopores

\section{INTRODUCTION}

Magnetron sputtered chromium aluminum nitride (CrAlN) films are excellent candidates for advanced machining and protection for high temperature applications (Reiter et al., 2005; Endrino et al., 2007; Wang et al., 2008). The fundamental reasons are the increased thermal stability (Willmann et al., 2006; Barshilia et al., 2009), mechanical properties (Hasegawa et al., 2005; Barshilia et al., 2006), and oxidation resistance (Banakh et al., 2003; Kawate et al., 2003; Brizuela et al., 2005; Braun et al., 2010; Escobar Galindo et al., 2010) in comparison to the binary CrN coating. $\mathrm{CrN}$ experiences a fast oxidation over $700^{\circ} \mathrm{C}$, where the properties of hardness and corrosion resistance decrease rapidly (Mège-Revil et al., 2009). The oxidation resistance can be enhanced above $800-900^{\circ} \mathrm{C}$ with reasonably minor amounts of aluminum (Al) additions into the $\mathrm{Cr}_{1-x} \mathrm{Al}_{x} \mathrm{~N}$ coating (Sánchez-López et al., 2005a; Rojas et al., 2012) although optimizing its content can yield a further improved oxidation (Lin et al., 2008; Mayrhofer et al., 2008). The upper critical limit is found around $x=0.6-0.8$ (depending on the deposition conditions), where the structure of $\mathrm{Cr}_{1-x} \mathrm{Al}_{x} \mathrm{~N}$ changes from the face-centered cubic $\mathrm{B} 1$ $(\mathrm{NaCl})$ to the hexagonal closed-packed B4 (wurtzite), which is accompanied by a decrease in hardness and wear performance. The protective effect against oxidation lies in the

Received May 17, 2013; accepted December 4, 2013

${ }^{\star}$ Corresponding author. E-mail: tcrojas@icmse.csic.es formation of complex $\mathrm{Al}$ and chromium $(\mathrm{Cr})$ oxide scales, which eventually suppress the oxygen diffusion into the bulk and the outward diffusion of metallic cations (SánchezLópez et al., 2005a; Lin et al., 2008; Mayrhofer et al., 2008; Mège-Revil et al., 2009; Braun et al., 2010; Sánchez et al., 2010; Rojas et al., 2012).

Recently, much attention has been paid to the incorporation of yttrium (Y) to ternary nitride films. Adding $\mathrm{Y}$ as a reactive element has been demonstrated to decrease the oxidation rate and to modify the oxide growth mechanism. The main effect of $\mathrm{Y}$ on transport processes may be the inhibition of cation diffusion along oxide grain boundaries (Prescott \& Graham, 1992). Moreover, it is suggested that Y favors the scale adhesion because the oxides protrude into the film. Y-containing cubic $\mathrm{Cr}_{1-x} \mathrm{Al}_{x} \mathrm{~N}$ films were shown to exhibit improved oxidation resistance up to temperatures exceeding $1,000^{\circ} \mathrm{C}$ when the $\mathrm{Y}$ content did not exceed around 1 at\% ( $2 \mathrm{~mol} \% \mathrm{YN}$ ) (Rovere et al., 2008; Brizuela et al., 2009). However, the location and chemical state of the $\mathrm{Y}$ atoms in the complex nanostructured and nanocomposite films are still open questions.

Another important parameter is tailoring architecture to combine the benefits of advanced ternary or quaternary metal nitrides with the enhanced performance obtained by controlled modulation at the nanoscale. Nanocomposite and multi-layered coatings have been demonstrated to provide superior hardness, toughness, tribological, and oxidation resistance thanks to phase separation and defined 
interfaces at the nanoscale level (Hovsepian et al., 2000, 2006; Musil et al., 2008; Steyer et al., 2008; Veprek \& Veprek-Heijman Maritza, 2008). This increased overall performance proceeds by different mechanisms such as the Hall-Petch effect, the numbers of interfaces that act as obstacles for the crack propagation, and the inward and outward diffusions of atomic species between the layers, among other factors. Different CrN-based multilayer systems like CrN/AlN (Tien et al., 2010; Cabrera et al., 2011), WC/CrAlN (Lee et al., 2002), CrN/CrAlN (Barshilia et al., 2007), TiAlN/CrAlN (Barshilia et al., 2009), and TiAlSiN/ CrAlN (Fukumoto et al., 2009) have been deposited showing improvement of mechanical properties and oxidation resistance compared with the single layer $\mathrm{CrN}$ and CrAlN coatings. The influence of the location of the metallic elements inside the ternary or quaternary nitrides and their chemical state may have a significant influence on the oxidation behavior and protective mechanism.

In some cases, although the formation of a multilayer structure was not sought on purpose, it appeared as a result of the sequential exposure of the substrate to the material fluxes generated by magnetrons during rotation (Panjan et al., 2008, 2009), especially in semi-industrial chambers with multiple rotation. This is particularly important when dealing with scaling-up for industrial processing. Multilayered nanostructure has been previously reported (Ross et al., 2010) in CrAlYN layers where the observed contrast is because of alternating CrAlYN/CrN bilayers. In our previous paper (Rojas et al., 2012) we also showed a multilayered nanostructure in CrAlYN coatings and further studies were needed to assess the nanostructure and chemical distribution of the CrAlYN components in these coatings. This work reports on the investigation of two series of CrAlYN coatings deposited by the magnetron sputtering technique using different deposition parameters aiming to elucidate the influence of the synthesis conditions on the microstructure and chemical composition. The location and chemical state of $\mathrm{Al}$ and $\mathrm{Y}$ atoms in these nanostructured coatings are not well known and are a great experimental challenge owing to their low concentration. Several transmission electron microscopy (TEM) techniques have been used in order to fully characterize and correlate the layered nanostructure, the present phases, and the elemental distribution with nanoscale resolution, in particular, for the dopant elements $\mathrm{Al}$ and $\mathrm{Y}$, as a function of the deposition parameters used.

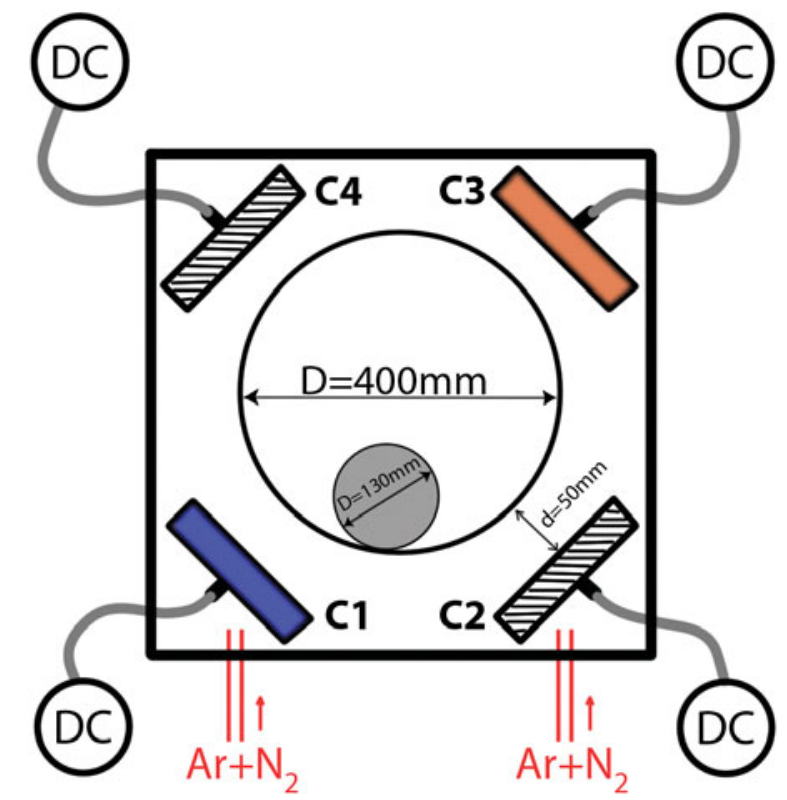

Figure 1. Scheme of the target distribution in the deposition chamber and planetary sample holder.

The role that this singular nanostructure can play in the demonstrated high-temperature oxidation resistance of these coatings is proposed.

\section{Materials and Methods}

\section{Sample Deposition}

CrAlYN coatings were prepared on Si (100) substrates by direct current magnetron sputtering using $\mathrm{Ar} / \mathrm{N}_{2}$ mixtures in commercial equipment (CemeCon $\left.{ }^{\circledR} \mathrm{CC} 800 / 8\right)$ provided with four rectangular targets $(200 \times 88 \times 5 \mathrm{~mm})$. A schematic diagram of the deposition system is shown in Figure 1. $\mathrm{Cr}$ (99.9\% purity), $\mathrm{Al}$ (99.5\% purity), and Y (99.5\% purity) targets were used. The sputtering power was set at $3,000 \mathrm{~W}$ for $\mathrm{Cr}$ and $\mathrm{Al}$ targets whilst 1,500 or $3,000 \mathrm{~W}$ was employed for the $\mathrm{Y}$ target. The target configuration in the chamber, the applied power, and the rotation speeds of the prepared samples (labelled as A, B, C, D, and E) are summarized in Table 1. Two series of samples were prepared: (set I) $\mathrm{A}, \mathrm{B}$, and $\mathrm{C}$ deposited using two $\mathrm{Cr}$, one $\mathrm{Al}$, and one $\mathrm{Y}$ targets; (set II), samples D and E, where a $\mathrm{Cr}$ target was replaced by $\mathrm{Al}$ in order to increase the $\mathrm{Al}$ content. The base

Table 1. Synthesis Conditions of the CrAlYN Coatings Prepared by Magnetron Sputtering: Target Materials, Power and Rotation Speeds ( $\omega_{1}$ : Turntable; $\omega_{2}$ : Tower) Applied to the Planetary Sample Holder.

\begin{tabular}{lccccccccccc}
\hline Sample & Set & $\mathrm{C} 1$ & $\begin{array}{c}\text { Power } \\
(\mathrm{W})\end{array}$ & $\mathrm{C} 2$ & $\begin{array}{c}\text { Power } \\
(\mathrm{W})\end{array}$ & $\mathrm{C} 3$ & $\begin{array}{c}\text { Power } \\
(\mathrm{W})\end{array}$ & $\mathrm{C} 4$ & $\begin{array}{c}\text { Power } \\
(\mathrm{W})\end{array}$ & $\begin{array}{c}\omega_{1} \\
(\mathrm{rpm})\end{array}$ & $\begin{array}{c}\omega_{2} \\
(\mathrm{rpm})\end{array}$ \\
\hline $\mathrm{A}$ & $\mathrm{I}$ & $\mathrm{Cr}$ & 3,000 & $\mathrm{Y}$ & 1,500 & $\mathrm{Cr}$ & 3,000 & $\mathrm{Al}$ & 3,000 & 0.75 & 2.07 \\
$\mathrm{~B}$ & & $\mathrm{Cr}$ & 3,000 & $\mathrm{Y}$ & 1,500 & $\mathrm{Cr}$ & 3,000 & $\mathrm{Al}$ & 3,000 & 1.20 & 3.33 \\
$\mathrm{C}$ & & $\mathrm{Cr}$ & 3,000 & $\mathrm{Y}$ & 3,000 & $\mathrm{Cr}$ & 3,000 & $\mathrm{Al}$ & 3,000 & 1.20 & 3.33 \\
$\mathrm{D}$ & $\mathrm{II}$ & $\mathrm{Cr}$ & 3,000 & $\mathrm{Al}$ & 3,000 & $\mathrm{Y}$ & 1,500 & $\mathrm{Al}$ & 3,000 & 1.20 & 3.33 \\
$\mathrm{E}$ & & $\mathrm{Cr}$ & 3,000 & $\mathrm{Al}$ & 3,000 & $\mathrm{Y}$ & 3,000 & $\mathrm{Al}$ & 3,000 & 1.20 & 3.33 \\
\hline
\end{tabular}



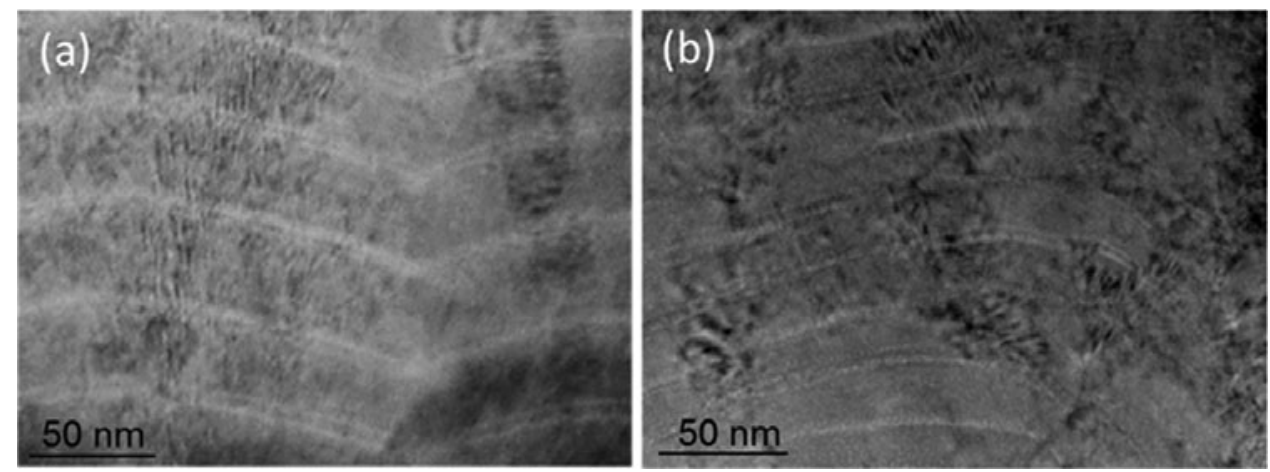

Figure 2. High magnification bright-field transmission electron microscopy images showing the multilayer structure of samples A (a) and B (b).

pressure of the vacuum chamber was $\sim 1 \times 10^{-4} \mathrm{~Pa}$ and the working pressure $1 \mathrm{~Pa}$, with an $\mathrm{Ar} / \mathrm{N}_{2}$ ratio of 1.5. The sample holder was negatively biased in the range of $110-120 \mathrm{~V}$ and the measured temperature span from 200 to $400^{\circ} \mathrm{C}$. The film thickness values typically vary in the $2-3 \mu \mathrm{m}$ range.

\section{Sample Characterization}

Chemical composition of the samples was obtained by electron probe microanalysis (EPMA). The EPMA equipment was a JEOL JXA-8200 SuperProbe instrument equipped with four wavelength-dispersive detectors and one energydispersive X-ray (EDS) spectrometer.

For TEM characterization cross-sectional specimens were prepared in the conventional manner by mechanical polishing followed by $\mathrm{Ar}^{+}$ion milling to electron transparency using an ion etching milling system from Fischione Instruments (model 1010). A Zeiss Auriga focused ion beam was used to prepare a cross-section lamella of sample C. To get information about the microstructure, the chemical composition, the phases formed, and the bonding types of the coatings, several TEMs were used: A Philips CM200 operating at $200 \mathrm{kV}$, with a parallel spectrometer from Gatan (model 766-2k). Electron energy loss spectra were recorded in diffraction mode with a spectrometer collection angle of $1.45 \mathrm{mrad}$, a camera length of $470 \mathrm{~nm}$ and a $2 \mathrm{~mm}$ spectrometer entrance aperture. Under these conditions the energy resolution of the coupled microscope/spectrometer system was $\sim 1.2 \mathrm{eV}$. After experimental acquisition the electron energy loss spectroscopy (EELS) spectra were processed using Gatan EL/P software for background subtraction, plural scattering deconvolution, and normalization to the continuum level after the core-loss edges of interest. Selected area electron diffraction (SAED) patterns of the samples were also recorded.

A JEOL JEM 2010F field emission gun scanning transmission electron microscope (STEM) operating at $200 \mathrm{kV}$ with a high angle annular dark field (HAADF) detector and a Gatan imaging filter (GIF-2000) was also used. EELS spectra were measured in STEM mode where a $0.5 \mathrm{~nm}$ beam with a current of 0.1-0.3 nA scanned several lines along the sample C. The HAADF signal was also simultaneously collected at each point within the lines scanned.
A Zeiss LIBRA 200HR STEM with an HAADF, an Omega filter, and an EDS (Oxford Instruments) detector was used to acquire series of energy-filtered TEM (EFTEM) images and a series of EDS spectra in scanning mode of sample C. EFTEM elemental maps using the three-windows method were acquired at $\mathrm{Cr}_{2,3}$-edge, $\mathrm{O} \mathrm{K}$-edge, and $\mathrm{N}$ K-edge.

A JEOL JEM 3100F UHR STEM operating at $300 \mathrm{kV}$, with HAADF and EDS (Oxford Instruments) detectors was used to do high-resolution TEM (HRTEM) and EDS area scans of $\mathrm{Al}, \mathrm{Cr}$, and $\mathrm{Y}$ of sample $\mathrm{C}$.

The Gatan Digital Micrograph software was used to measure lattice spacings and to calculate digital diffractograms. The program Eje-Z (Perez-Omil, 1994) was used to analyze digital diffraction patterns (DDP) and to identify different phases.

\section{Results AND Discussion}

\section{Morphology and Nanostructure of Coatings}

In a previous TEM study of coating A, shown in Rojas et al. (2012), we demonstrated that this coating grows forming a polycrystalline columnar microstructure constituted by the cubic $\mathrm{Cr}(\mathrm{Al}, \mathrm{Y}) \mathrm{N}$ phase. In Figure 2a, a bright field (BF) TEM image of sample A shows the multilayered nanostructure inside the columns. Layers of $25-30 \mathrm{~nm}$ thick appear separated by two thin layers of $1.5-2 \mathrm{~nm}$ in thickness with brighter contrast. The TEM study of the remaining samples (B-E) revealed the same multilayer nanostructure as sample A. Figure $2 \mathrm{~b}$ shows a BF TEM image corresponding to sample B. A decrease of the layer thickness (15$20 \mathrm{~nm}$ ) is observed because of the increase of the rotation speeds $\left(\omega_{1}\right.$ : turntable; $\omega_{2}$ : tower). This thickness decrease was also observed in the remaining samples.

To further investigate the origin of this layered contrast, the HAADF/STEM technique was used. The images were formed from the very high angle incoherently scattered electrons that have suffered a Rutherford scattering. The pixel intensity in the HAADF images is proportional to the atomic number $Z$ and/or local density (often named as $Z$-contrast images). In Figure 3a, a HAADF image of a very thin area of sample $\mathrm{C}$ is shown. Looking at this picture, 

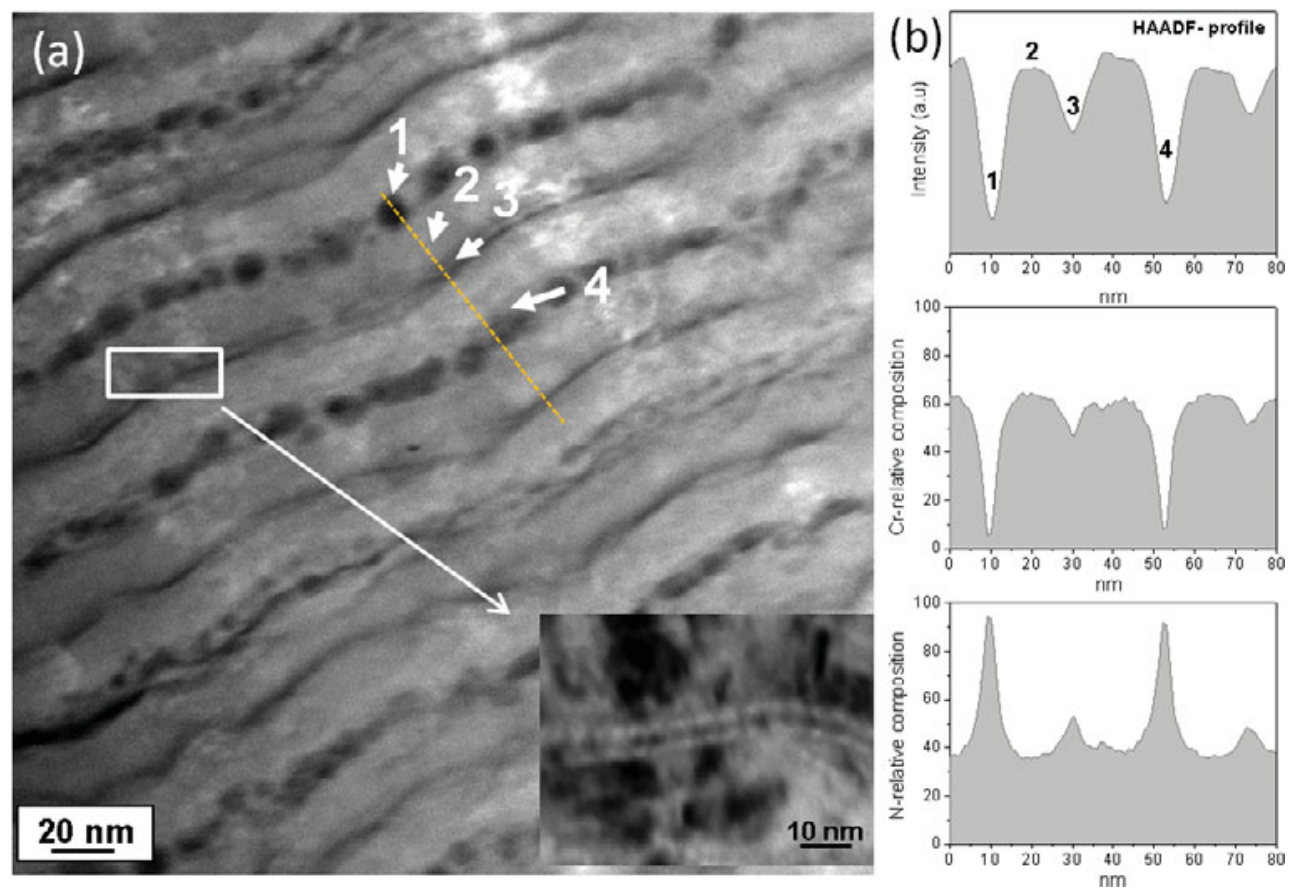

Figure 3. a: High angle annular dark field (HAADF) image of sample $\mathrm{C}$ revealing the ordered pore layers. Four marked positions 1,2,3, and 4 have been selected along a profile perpendicular to the multilayer structure; the inset shows a high magnification bright-field transmission electron microscopy image of the marked area. b: HAADF signal variation and $\mathrm{Cr}$ and $\mathrm{N}$ relative chemical composition along the marked profile.
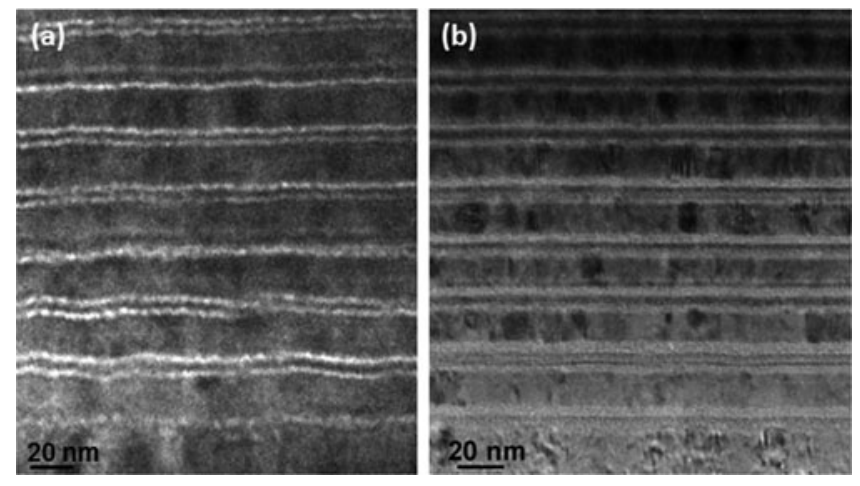

Figure 4. High magnification bright-field transmission electron microscopy images of samples D (a) and E (b).

layers with dark contrast (bright contrast in BF image) of two alternating thicknesses can be observed. Thicker layers are formed by aligned nanospheres of around 6-8 $\mathrm{nm}$ and the thinner one of around 1-2 $\mathrm{nm}$. The profile of the HAADF signal (cf. Fig. 3b) obtained along the marked line also shows that the intensity decreases to very low levels on the spherical features ( 1 and 4$)$ suggesting that the nanospheres are actually pores. A high magnification BF TEM image of this layer (inset in Fig. 3a) reveals that is formed by two thin lines containing small pores of 1-2 $\mathrm{nm}$.

Figures $4 \mathrm{a}$ and $4 \mathrm{~b}$ show BF TEM images of the samples $\mathrm{D}$ and $\mathrm{E}$ (set II), respectively, which were synthesized using different $Y$ target powers. In Figure $4 a$, a bright double layer with an approximate thickness of $2 \mathrm{~nm}$ each is repeated every $15-18 \mathrm{~nm}$, and in some points, spherical features can be identified. Likewise, in sample E, the bright thin layers are slightly thicker, around 3-4 $\mathrm{nm}$ each, with the same periodicity of sample D. Similar morphological features were observed in samples B and C (set I), which indicates that by increasing the $\mathrm{Y}$ target power the thickness of the bright thin bilayers increases.

\section{Chemical and Phase Composition}

Several spectroscopy and microscopy techniques have been used to study the chemical composition, elemental distribution, and phases present at different scales in the coatings. Table 2 summarizes the atomic composition measured by EPMA of all samples and shows that the increase in number of $\mathrm{Al}$ targets and the increase of power applied to the $\mathrm{Y}$ target lead to an increment of $\mathrm{Al}$ and $\mathrm{Y}$ concentration, respectively. In Figure 5 we have included the SAED measured for the samples under study. The patterns reveal the existence in all the samples of diffraction rings corresponding to the (111), (200), and (220) planes of the $\mathrm{c}-\mathrm{Cr}(\mathrm{Al}) \mathrm{N}$ phase. A preferred orientation of the crystals is noticed in the case of the (200) diffraction ring. In the case of the samples $\mathrm{C}$ and $\mathrm{E}$ with much higher $\mathrm{Y}$ content, diffraction rings also appear at 2.8 and $1.7 \AA$, that can be assigned to the (111) and (220) planes of c-YN. This phase also presents a ring at $2.4 \AA$ assigned to the (200) planes that overlap with that of the c-CrN phase.

EELS spectroscopy can be used to assess the local crystal/electronic structure as well as the local composition of a sample. In particular, we have done electron energy-loss near-edge structure to determine the phase, in which an 
Table 2. Elemental Chemical Composition of the CrAlYN Coatings Measured by EPMA and $\Delta I, \Delta E$ Parameters Obtained from N-K EELS Spectra.

\begin{tabular}{lccccccrr}
\hline Sample & Set & Cr (at\%) & Al (at\%) & N (at\%) & Y (at\%) & $\Delta I$ & $\Delta E$ & $\beta$ \\
\hline A & I & 38.6 & 5.1 & 54.6 & 1.7 & 0.82 & 9.4 & 6.6 \\
B & & 40.1 & 4.0 & 54.3 & 1.6 & 0.84 & 9.7 & 5.2 \\
C & & 39.3 & 3.6 & 53.4 & 3.6 & 0.85 & 9.8 & 5.1 \\
D & II & 32.7 & 11.8 & 53.4 & 2.2 & 0.73 & 8.4 & 12.6 \\
E & & 31.5 & 11.5 & 52.0 & 5.0 & 0.74 & 8.8 & 12.7 \\
CrN-MS & Ref. & 45.6 & - & 54.4 & - & 0.94 & 10.8 & - \\
\hline
\end{tabular}

element is present (Mackenzie et al., 2005; Sánchez-López et al., 2005b; Abad et al., 2011; Holec et al., 2011; Godinho et al., 2012b).

In Figure 6 we have depicted for each sample A to E the experimental $\mathrm{N}-\mathrm{K}$ edge EELS spectra normalized to the edge jump and after aligning the first peak at $400 \mathrm{eV}$. We used as ELNES references or "fingerprints" the spectrum measured on a sample of $\mathrm{CrN}$ prepared by magnetron sputtering (CrN-MS) and the spectrum of bulk crystalline c-AlN presented in Mackenzie et al. (2005). Figure 6 shows that the intensities of the first and second peak of the spectra at 400 and $\approx 410 \mathrm{eV}$, respectively, suffer small changes. A decrease in the intensity of the first peak is associated with the presence of $\mathrm{N}$-Al bonding, either forming a c-AlN phase or a c-CrAlN phase (Ross et al., 2010). In addition, an energy shift of the second peak is observed that can be related with a change in crystal lattice parameter (Craven, 1995). It is expected that a shift to lower energies when the lattice parameter decreases (i.e., more $\mathrm{Al}$ incorporation) will occur. To make the comparison between EELS spectra easier we have calculated the ratio of intensities $\Delta I=I_{1} / I_{2}$, where
$I_{1}$ is the maximum intensity of the first peak at $400 \mathrm{eV}$ and $I_{2}$ is the intensity of the second around $410 \mathrm{eV}$. Likewise, we can define $\Delta E=E_{2}-E_{1}$ as the measured energy difference between these two intensity maxima for all the spectra.

The obtained values are summarized in Table 2 . We observe a variation of $\Delta I$ from 0.94 (CrN-MS) to 0.73 for the film containing the maximum $\mathrm{Al}$ content (sample $\mathrm{D}$ ). Using the measured values $\Delta I$ for all the samples, and the spectra of $\mathrm{CrN}$ and c-AlN references we can estimate the fraction of $\mathrm{Al}$ present in cubic environments (hereafter $\beta$ ). The obtained values are included in Table 2 and follow in good agreement the Al contents measured by EPMA. Samples from set II exhibit a strong decrease of the intensity of the first peak, as expected by the higher Al contents, but also a widening of the peaks, which can be related with a decrease in the crystalline order and/or to the presence of amorphous nitride phases. Regarding the change of $\Delta E$ a decrease from 9.4-9.8 (from set I) to 8.4-8.8 (from set II) is observed when the $\mathrm{Al}$ content is increased from 4-5 (set I) to $\sim 12$ at $\%$ (set II). In the case of sample $\mathrm{E}$, where the $\mathrm{Al}$ content is similar to sample $\mathrm{D}$, but with higher $\mathrm{Y}$ concentra-
SET I SampleA

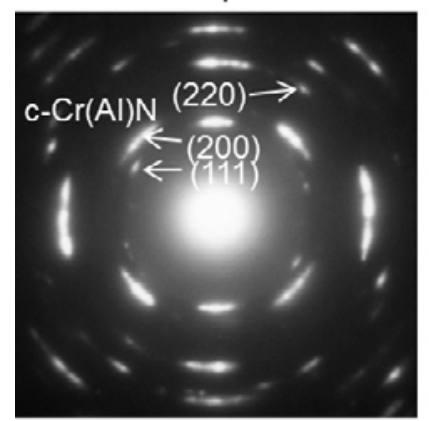

SET ॥
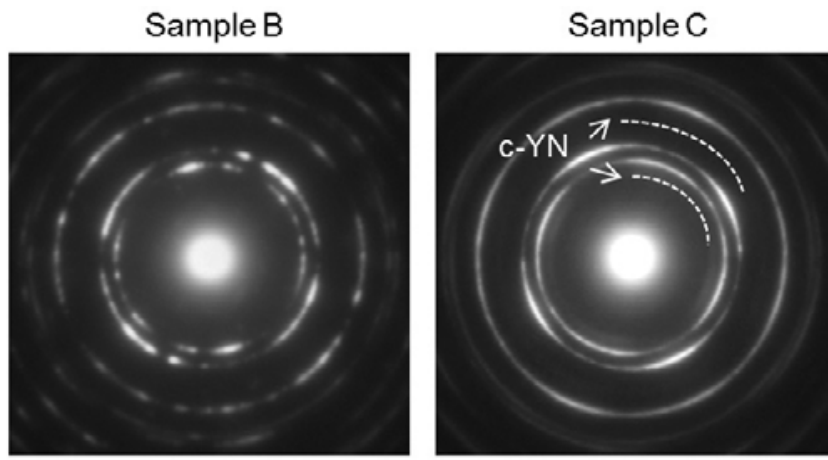

Sample E

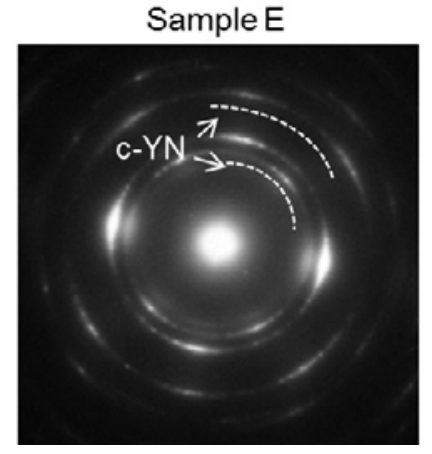

Sample D

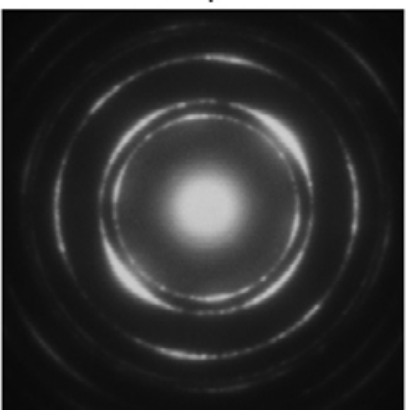

Figure 5. Selected area electron diffraction pattern of all CrAlYN coatings. 


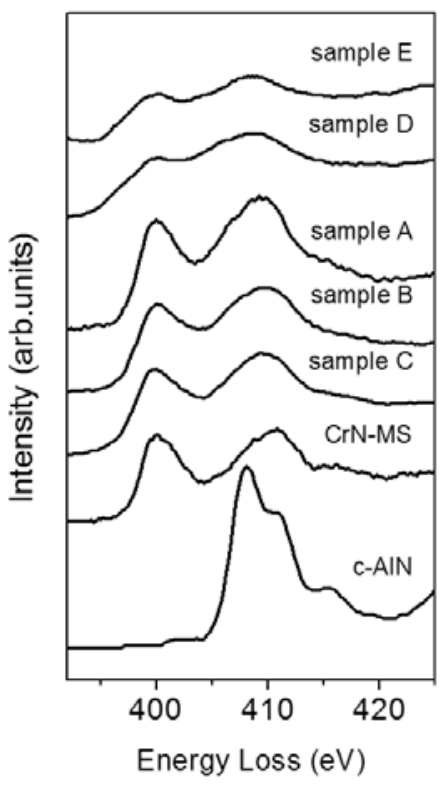

Figure 6. N K-edge electron energy loss spectroscopy spectra of CrAlYN coatings under study. The spectra measured for CrN prepared by magnetron sputtering (CrN-MS) and c-AlN reference compounds are included as fingerprints.

tion, the same value of $\Delta I$ and a bigger value of $\Delta \mathrm{E}$ are measured. This difference can be explained for an increase in the lattice parameter, by the presence of $\mathrm{YN}$ phase, as has been detected by SAED analysis. The same occurs in sample $\mathrm{C}$ in comparison to $\mathrm{B}$.

At this point we can propose that $\mathrm{Al}$ atoms are forming part of an amorphous AlN phase or substituting $\mathrm{Cr}$ atoms in the c-CrN lattice, forming a CrAlN solid solution, as proposed in previous publications (Hasegawa et al., 2005; Willmann et al., 2006; Lin et al., 2008; Mayrhofer et al., 2008; Rovere et al., 2008; Rojas et al., 2012). In addition, Y atoms form a CrYN solid solution and a crystalline c-YN phase in samples $\mathrm{C}$ and $\mathrm{E}$.

To further investigate the chemical elemental distribution a combination of spatially resolved microanalysis techniques was employed. $\mathrm{N}$ and $\mathrm{Cr}$ elemental maps were obtained from EFTEM images. Figures $7 \mathrm{a}$ and $7 \mathrm{~b}$ show the $\mathrm{Cr}$ and $\mathrm{N}$ elemental maps, respectively, from a thin area of sample $\mathrm{C}$ shown in Figure 3a. The multilayer structure is clearly observed with areas concurrently rich in $\mathrm{Cr}$ and $\mathrm{N}$, indicative of the presence of a $\mathrm{CrN}$ phase in the bright layers, separated by thinner lines where these elements are not dominant. Focussing on the Cr image, two types of dark lines can be observed. The larger is also coincident with $\mathrm{N}$ mapping and is congruent with the porous regions detected in BF images, but the thinner layer is not clearly seen in the $\mathrm{N}$ image. In order to establish the location of $\mathrm{Al}$ and $\mathrm{Y}$ atoms STEM-based EDS was used. EDS spectra line scans were taken perpendicular to the stack of layers with an electron probe size of $2 \mathrm{~nm}$ (shown in Fig. 7c). Al and Y profiles display alternating maxima and minima. Starting from the thicker dark layer in the $\mathrm{Cr}$ map (see marked arrow in Fig. 7c), the Y signal reaches its maximum intensity while the $\mathrm{Al}$ peak the least. The opposite situation is noticed when crossing over the second and thinner dark layer and so repeatedly. Therefore, it can be concluded that thicker dark bands correspond to regions richer in $\mathrm{Y}$, while the thinner dark layers are richer in $\mathrm{Al}$.

To get chemical and spectroscopic information with higher spatial resolution the STEM mode was used to measure an EELS line scan across the multilayer structure in sample $\mathrm{C}$ using a probe of less than $1 \mathrm{~nm}$. In Figure $3 \mathrm{~b}$ we have included the relative $\mathrm{Cr}$ and $\mathrm{N}$ composition along the depicted line together with the HAADF intensity profile. The $\mathrm{Cr}$ concentration follows a similar shape to the HAADF intensity profile. Interestingly, the $\mathrm{N}$ concentration fluctuates from average values of about $50 \%$ (yielding $\mathrm{Cr} / \mathrm{N}$ ratio $\approx 1$ ) to nearly $100 \%$ coincident with the porous region (points 1 and 4). The N-K edge EELS spectra measured in points 1, 2, and 3 marked in Figure 3 a are depicted in Figures $8 \mathrm{a}, 8 \mathrm{~b}$, and $8 \mathrm{c}$, respectively. A significant change in the $\mathrm{N}$ signal is observed. In the pore region (1), the $\mathrm{N}$ signal has a characteristic signature of molecular nitrogen. A small signal of $\mathrm{Cr}-\mathrm{L}_{2,3}$ is still detected as can be noticed in the region above $570 \mathrm{eV}$. Outside the pore, point 2, the spectrum shows a pattern characteristic of a $\mathrm{CrN}$ phase. Comparing point 2 with 3 , the intensity of the first peak of the $\mathrm{N}-\mathrm{K}$ edge experiences a clear decrease from $\Delta I=0.96$ to 0.61 and the value of $\Delta E$ decreases from 10.41 to $8.95 \mathrm{eV}$. The changes of these two parameters indicate the presence of more Al-N bonding in point 3. In fact, this area corresponds to the zones rich in $\mathrm{Al}$ detected by the EDS line scan. Therefore, this change is attributed to the presence of a c-AlN phase or CrAlN phase richer in Al. The calculated $\beta$ value 21.5 in this point supports this assumption.

Putting together all of these results, the complex layered architecture for samples from set I can be defined as the stacking of $\left[(\mathrm{CrYN} / \mathrm{YN})+\mathrm{N}_{2} / / \mathrm{CrN} / /(\mathrm{CrAlN} / \mathrm{AlN})+\mathrm{N}_{2}\right]$ sequences. This finding is crucial for understanding the chemical and microstructure characteristics of this multilayered system affecting the thermal and oxidation stability of this nanostructured system.

In the case of set II (samples D and E), the number of $\mathrm{Al}$ targets was doubled to increase the $\mathrm{Al}$ concentration in the coatings and placed between Y and Cr targets (cf. Fig. 1). The chemical composition and distribution across the multilayers are expected to change accordingly. The $\mathrm{Al}, \mathrm{Cr}$, and $\mathrm{Y}$ elemental mappings obtained by the STEM-based EDS area scan, using a probe size of around $0.5 \mathrm{~nm}$, of a selected area of sample D, are shown in Figure 9. A HAADF image of the scanned area is also included where the dark areas correspond to the pore zones. In the EDS chemical elemental maps a layered distribution is observed alternating areas rich in $\mathrm{Cr}$ with regions where $\mathrm{Y}$ and $\mathrm{Al}$ atoms are mixed. Comparing with the HAADF image, the thick and bright bands are due to the presence of $\mathrm{Cr}$ from $\mathrm{CrN}$ while the dark pore regions are enriched in $\mathrm{Al}$ and $\mathrm{Y}$ atoms. With the aim of obtaining further information about the crystalline phases present and their location, a HRTEM study was taken across these interfaces. 

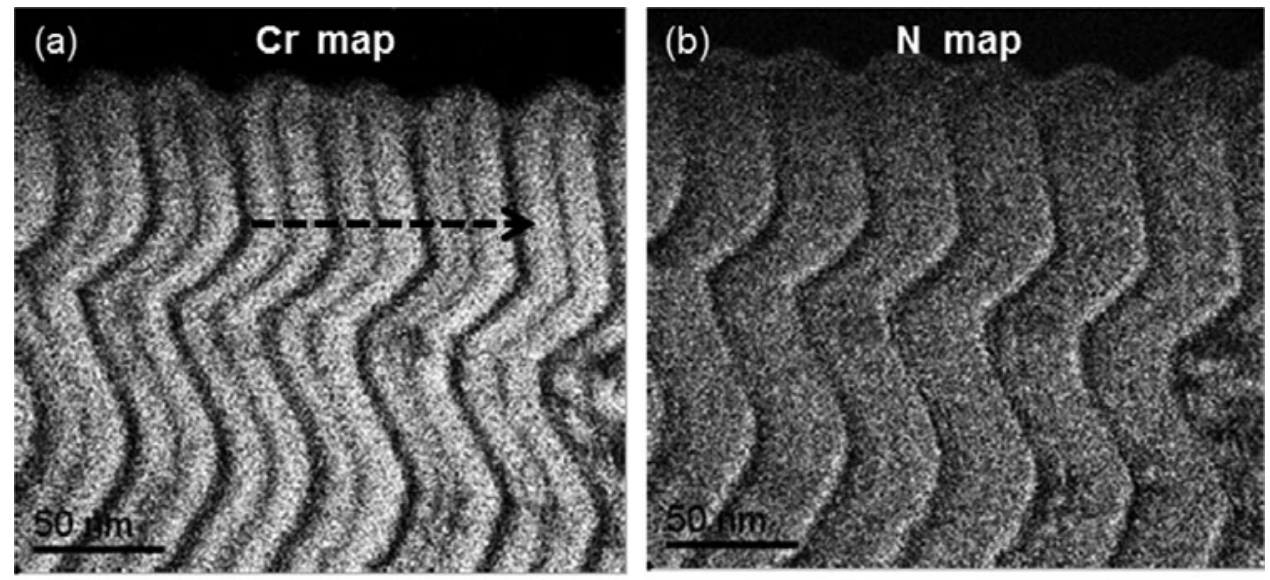

(c)
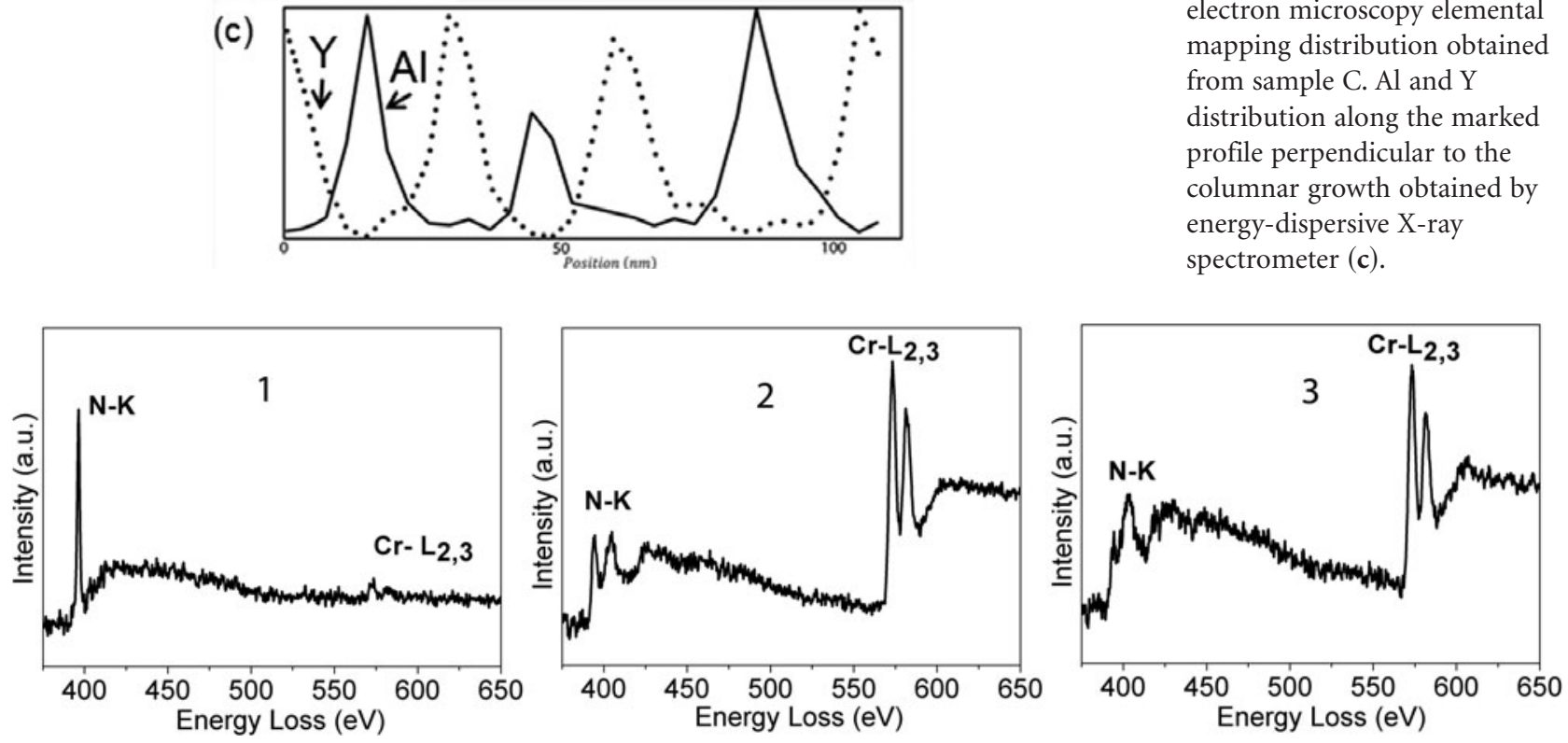

Figure 8. Electron energy loss spectroscopy spectra taken at 1, 2, and 3, marked positions in Figure 3a.

A HRTEM image of sample D is shown in Figure 10a. Two layers of higher contrast are denoted with some nanocrystals embedded whose measured $d$-spacing of the lattice fringes (2.3 and $2 \AA$ ) agrees with the (111) and (200) planes of the cubic CrN phase. Most of the interplanar distances correspond to (200) planes in agreement with the preferential growth mentioned before. Between these two dark nanocrystalline layers is an amorphous region composed of two brighter layers with a darker region in the middle of around $2 \mathrm{~nm}$. In this last thin layer some small nanocrystals of 1-2 $\mathrm{nm}$ are found. The measured $d$-spacing of these lattice fringes are $1.9 \AA$ that can be assigned to (200) planes of cubic-AlN phase or CrN phase, but taking into account the previous EDS elemental mappings, this region was richer in $\mathrm{Al}$ (mixed with $\mathrm{Y}$ in lower quantity) so we can conclude that they correspond to $\mathrm{c}-\mathrm{AlN}$ or $\mathrm{c}-\mathrm{CrAlN}$. In the upper part of Figure $10 \mathrm{a}$, a $d$-spacing of $2.4 \AA$ has been measured in the lighter layer taking into account the EDS mapping, could be assigned to a nanocrystal of c-YN.

In Figure 10b, a high magnification HRTEM image of the interface region (see marked area in Fig. 10a) is shown.
Figure 7. Cr (a) and N (b) energy-filtered transmission electron microscopy elemental mapping distribution obtained from sample $\mathrm{C}$. $\mathrm{Al}$ and $\mathrm{Y}$ distribution along the marked profile perpendicular to the columnar growth obtained by energy-dispersive X-ray spectrometer (c).
The insets in Figure 10 correspond to the DDP obtained from two marked crystalline areas. The values of 2.3, 2.0, and $1.4 \AA$ measured in the DDP's can be assigned to the (111), (200), and (220) planes, respectively, of the c-CrN crystals oriented along [001] and [011] zone axis for the A and $B$ insets, respectively. The EELS spectra measured in the porous layers of this coating (not shown) also demonstrated the presence of molecular nitrogen embedded in these areas. The results of the general N-K EELS shown in Figure 6 manifested a decrease of the first peak and peak widening, both phenomena are in agreement with the increment of the $\mathrm{Al}$ content and the presence of amorphous phases, respectively. In summary, for the highest $\mathrm{Al}$ contents (set II) the assembly of HREM, EDS mapping, and EELS results allows concluding that the $\mathrm{CrN}$ nanocrystalline layers are separated by a heterogeneous layer where some nanocrystals of c-AlN, $\mathrm{c}-\mathrm{YN}$, and pores filled with $\mathrm{N}_{2}$ molecules are embedded in an amorphous matrix mainly constituted by AlN phase. Taking into account the assembly of results obtained for Sets I and II, in Figure 11 we have depicted a schematic drawing summarizing the nanostructure of these sets of coatings. 

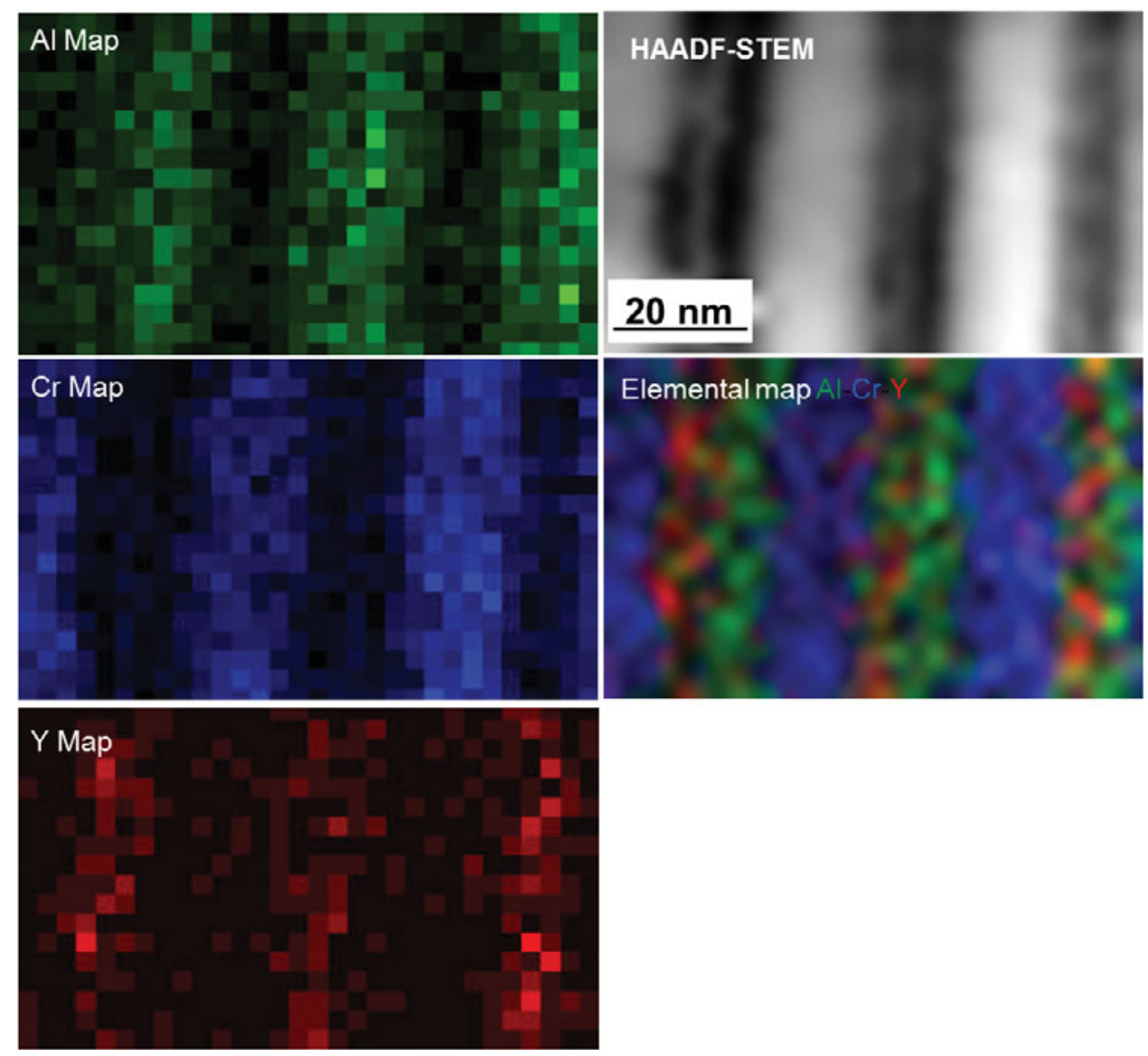

Figure 9. Chemical distribution mapping of $\mathrm{Cr}, \mathrm{Al}$, and $\mathrm{Y}$ elements obtained by energy-dispersive $\mathrm{X}$-ray spectrometer analysis for sample D.
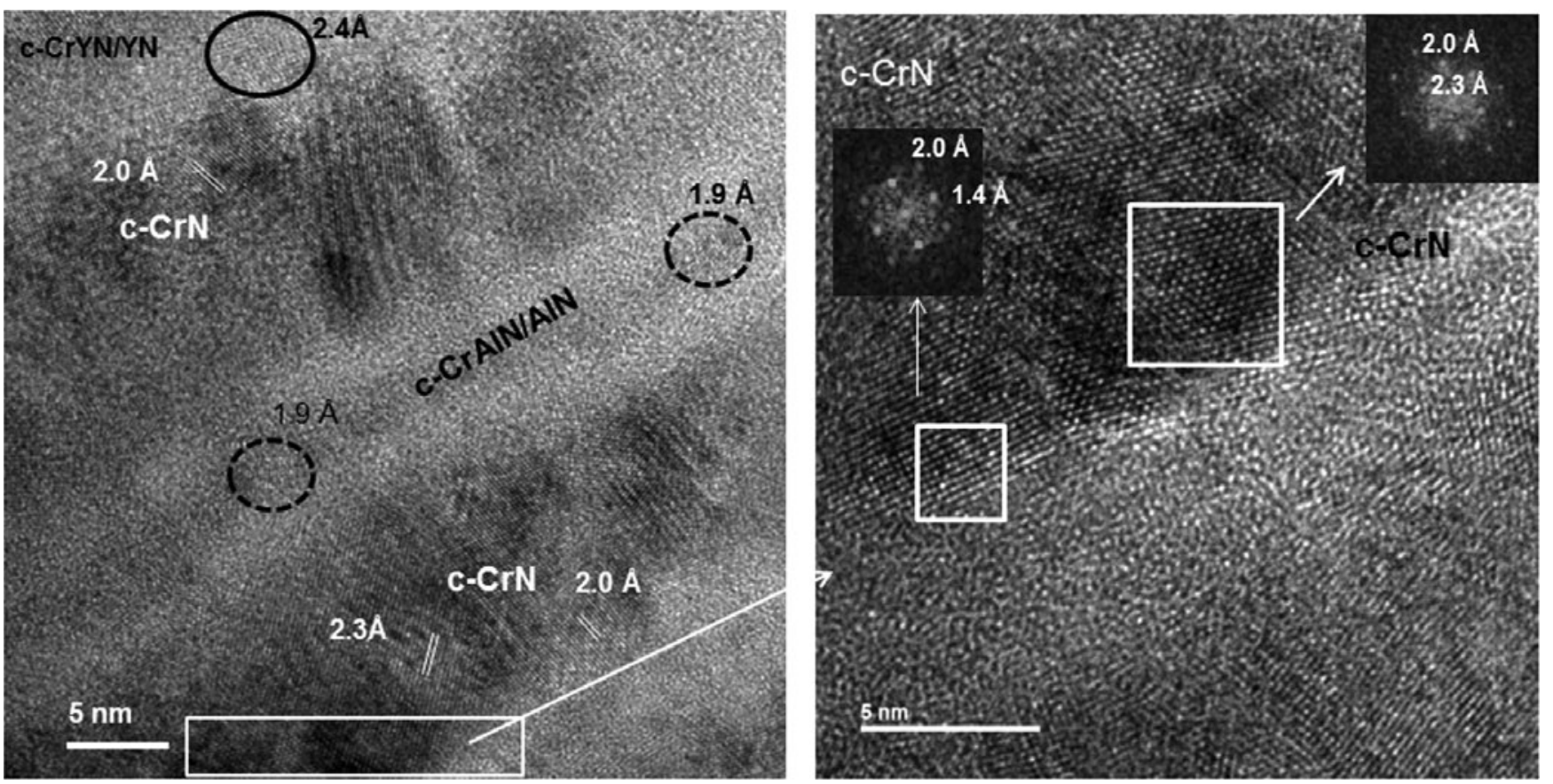

Figure 10. Left: High-resolution transmission electron microscopy image displaying the complex multi-layered structure of sample D. The d-spacings for several identified phases are marked in the micrograph. Right: Detail at higher magnification of the crystalline/amorphous interface. 


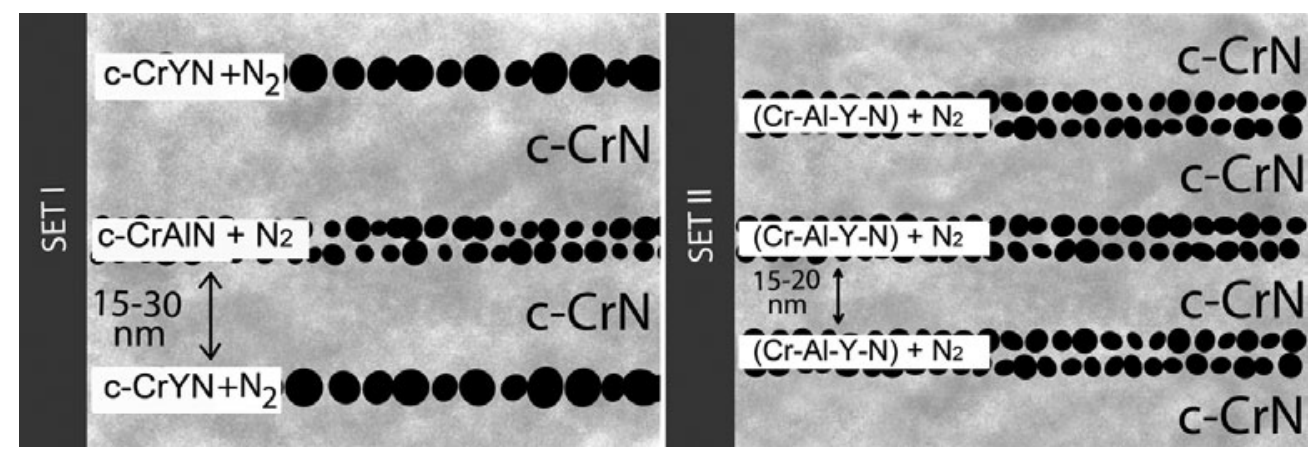

Figure 11. Scheme of the nanostructure and chemical distribution of the coatings from set I and set II.

Embedded nitrogen-filled nanovoids are consequently found periodically in our CrAlYN coatings prepared by magnetron sputtering. The presence of molecular nitrogen trapped in disordered and amorphous films has already been pointed out (Romero-Gomez et al., 2010; Godinho et al., 2012a) although the distribution was not periodic as observed here. This induced periodicity is likely a consequence of the position of the targets and the rotation of the samples. The reasons for the formation of these nitrogen bubbles can be found in the diffusion of nitrogen released from point-defects and dislocations generated during growth (Kucheyev et al., 2000; Ruck et al., 2004). The $\mathrm{N}$ atoms can migrate through these easy pathways and nucleates into the molecular form when they are stopped by crystalline or amorphous nitride interfaces that are formed with $\mathrm{Al}$ and $\mathrm{Y}$ targets. These embedded $\mathrm{N}_{2}$-filled nanovoid barriers may hinder ion diffusion during oxidation and maintain an inert environment at the $\mathrm{CrN}$ layer boundaries.

The changes in the deposition parameters have yielded to different $\mathrm{Al}$ and $\mathrm{Y}$ distribution and crystalline/amorphous interfaces. The thermal stability and oxidation resistance of sample $\mathrm{A}$ (set I), where the $\mathrm{Al}$ and $\mathrm{Y}$ are forming alternative periodic layers, was studied under heating up to $1,000^{\circ} \mathrm{C}$ (Rojas et al., 2012). The multilayer structure appeared preserved, proving the efficient blocking effect of the singular nanostructure found in this paper, which contains voids embedded in CrAlN and CrYN periodic layers. Further investigations are currently underway to correlate the influence of nanostructure and chemical distribution of the remaining samples on the oxidation rate and protectiveness.

\section{Conclusions}

The structure and chemical composition of complex multilayered CrAlYN coatings for high temperature applications are investigated using a variety of state-of-the-art TEM techniques. The multilayered structure is the result of the sequential exposure of the substrates to different target and plasma compositions. The main feature is the alternation of crystalline $\mathrm{CrN}$ layers with amorphous or crystalline regions where $\mathrm{Al}$ and/or $\mathrm{Y}$ are present. These elements appear mainly in the form of AlN and YN compounds although partial substitution in $\mathrm{CrN}$ phases cannot be ruled out. Ordered layers of nanovoids filled with molecular nitrogen appear embedded in this matrix. The stacking sequence varied depending on the nature, position of the targets, and the rotation speeds controlling the chemical composition and architecture of the multilayered system. The repartition of $\mathrm{Al}$ and $\mathrm{Y}$ nitrides in alternative periodic layers in samples from set $I$ is suggested to play an important role in the demonstrated high temperature oxidation resistance of these coatings as they can act as a sum of barrier layers to oxygen diffusion inwards. Moreover, the presence of periodic arrays of nitrogen bubbles may help to block ion transport and to maintain an inert environment at the $\mathrm{CrN}$ layer boundaries during oxidation.

\section{ACKNOWLEDGMENTS}

The Spanish MINECO (projects No. MAT2011-29074-C0201/-02, CONSOLIDER FUNCOAT CSD2008-00023), CSIC (20160I041), and European Union (CT-REGPOT-2011-1285895 AL-NANOFUNC) are acknowledged for financial support. The contributions of Dr. Alexander Orchowisk and Dr. Katja Etzel from Application Carl Zeiss NTS Gmbh, Mr. Cailler from JEOL (Europe) SAS, and Mr. Aoki from JEOL USA, are gratefully acknowledged.

\section{REFERENCES}

Abad, M.D., Sanjinés, R., Endrino, J.L., Gago, R., Andersson, J. \& SÁnchez-López, J.C. (2011). Identification of ternary phases in TiBC/a-C nanocomposite thin films: Influence on the electrical and optical properties. Plasma Process Polym 8(7), 579-588.

Banakh, O., Schmid, P.E., Sanjinés, R. \& Lévy, F. (2003). Hightemperature oxidation resistance of $\mathrm{Cr}_{1-\mathrm{x}} \mathrm{Al}_{\mathrm{x}} \mathrm{N}$ thin films deposited by reactive magnetron sputtering. Surf Coat Technol 163164, 57-61.

Barshilia, H.C., Deepthi, B., Rajam, K.S., Bhatti, K.P. \& Chaudhary, S. (2009). Growth and characterization of superlattices prepared by reactive direct current magnetron sputtering. J Vac Sci Technol A 27, 29-33.

Barshilia, H.C., Deepthi, B., Selvakumar, M., Jain, A. \& RaJAM, K.S. (2007). Nanolayered multilayer coatings of CrN/ CrAlN prepared by reactive DC magnetron sputtering. Appl Surf Sci 253, 5076-5083.

Barshilia, H.C., Selvakumar, N., Deepthi, B. \& Rajam, K.S. (2006). A comparative study of reactive direct current magnetron sputtered CrAlN and CrN coatings. Surf Coat Technol 201, 2193-2201 
Braun, R., Rovere, F., Mayrhofer, P.H. \& Leyens, C. (2010). Environmental protection of $\gamma$-TiAl based alloy Ti-45Al-8Nb by CrAlYN thin films and thermal barrier coatings. Intermetallics 18, 479-486.

Brizuela, M., García-Luis, A., Braceras, I., OÑate, J.I., SÁnchezLópez, J.C., Martínez-Martínez, D., López-Cartes, C. \& FernándeZ, A. (2005). Magnetron sputtering of $\mathrm{Cr}(\mathrm{Al}) \mathrm{N}$ coatings: Mechanical and tribological study. Surf Coat Technol 200(1-4), 192-197.

Brizuela, M., García-Luis, A., Corengia, P., GonzálezSantamaría, D., Muñoz, R. \& GonzÁlez, J.J. (2009). Microstructural, mechanical and tribological properties of CrAlYN coatings deposited by magnetron sputtering. Plasma Process Polym 6, 162-167.

Cabrera, G., Caicedo, J.C., Amaya, C., Yate, L., Muñoz Saldaña, J.C. \& Prieto, P. (2011). Enhancement of mechanical and tribological properties in AISI D3 steel substrates by using a non-isostructural CrN/AlN multilayer coating. Mater Chem Phys 125, 576-586.

Craven, A.J. (1995). The electron energy-loss near-edge structure (ELNES) on the $\mathrm{N}$ K-edges from the transition metal mononitrides with the rock-salt structure and its comparison with that on the $\mathrm{C}$ K-edges from the corresponding transition metal monocarbides. J Microsc 180(3), 250-262.

Endrino, J.L., Fox-Rabinovich, G.S., Reiter, A., Veldhuis, S.V., Escobar Galindo, R., Albella, J.M. \& Marco, J.F. (2007). Oxidation tuning in AlCrN coatings. Surf Coat Technol 201(8), 4505-4511.

Escobar Galindo, R., Endrino, J.L., Martínez, R. \& Albella, J.M. (2010). Improving the oxidation resistance of AlCrN coatings by tailoring chromium out-diffusion. Spectrochim Acta Part B 65, 950-958.

Fukumoto, N., Ezura, H. \& Suzuki, T. (2009). Synthesis and oxidation resistance of TiAlSiN and multilayare TiAlSiN/ CrAlN coating. Surf Coat Technol 204, 902-906.

Godinho, V., Rojas, T.C. \& Fernández, A. (2012a). Magnetron sputtered $\mathrm{a}-\mathrm{SiO}_{\mathrm{x}} \mathrm{N}_{\mathrm{y}}$ thin films: A closed porous nanostructure with controlled optical and mechanical properties. Micropor Mesopor Mater 149, 142-146.

Godinho, V., Rojas, T.C., Trasobares, S., Ferrer, F.J., Delplancke-Ogletree, M.P. \& Fernández, A. (2012b). Microstructural and chemical characterization of nanostructured TiAlSiN. Microsc Microanal 18, 1-14.

Hasegawa, H., Kawate, M. \& Suzuki, T. (2005). Effects of Al contents on microstructures of $\mathrm{Cr}_{1-x} \mathrm{Al}_{x} \mathrm{~N}$ and $\mathrm{Zr}_{1-x} \mathrm{Al}_{x} \mathrm{~N}$ films synthesized by cathodic arc method. Surf Coat Technol 200, 2409-2413.

Holec, D., Rachbauer, R., Kiener, D., Cherns, P.D., Costa, P.M.F.J., Mcaleese, C., Mayrhofer, P.H. \& Humphreys, C.J. (2011). Towards predictive modelling of near-edge structures in electron energy loss spectra of AlN based ternary alloys. Phys Rev B 83(16), 165122-165132.

Hovsepian, P.E.H., Lewis, D.B. \& Münz, W.D. (2000). Recent progress in large scale manufacturing of multilayer/superlattice hard coatings. Surf Coat Technol 133-134, 166-175.

Hovsepian, P.E.H., Reinhard, C. \& Ehiasarian, A.P. (2006). CrAlYN/CrN superlattice coatings deposited by the combined high power impulse magnetron sputtering/unbalanced magnetron sputtering technique. Surf Coat Technol 201, 4105-4110.

Kawate, M., Hashimoto, A.K. \& Suzuki, T. (2003). Microstructure and mechanical properties of CrAlN coatings deposited by modified ion beam enhanced magnetron sputtering on AISI H13 steel. Surf Coat Technol 165, 163-167.

Kucheyev, S.O., Williams, J.S., Zou, J., Jagadish, C. \& Li, G. (2000). Ion-beam-induced dissociation and bubble formation in GaN. Appl Phys Lett 77(22), 3577-3579.

Lee, H.Y., Han Jeon, G., Baeg Seung, H. \& Yang, S.E.H. (2002). Structure and properties of WC-CrAlN superlattice films by cathodic arc ion plating process. Thin Solid Films 420-421, 414-420.

Lin, J., Mishra, B., Moore, J.J. \& Sproul, W.D. (2008). A study of the oxidation behavior of $\mathrm{CrN}$ and $\mathrm{CrAlN}$ thin films in air using DSC and TGA analyses. Surf Coat Technol 202, 3272-3283.

Mackenzie, M., Weatherly, G.C., Mccomb, D.C. \& Craven, A.J. (2005). Electron energy loss spectroscopy of a TiAIN coating on stainless steel. Scripta Materialia 53, 983-987.

Mayrhofer, P.H., Music, D., Reeswinkel, T.H., Fuss, H.G. \& Schneider, J.M. (2008). Structure, elastic properties and phase stability of $\mathrm{Cr}_{1-\mathrm{x}} \mathrm{Al}_{\mathrm{x}} \mathrm{N}$. Acta Mater 56, 2469-2475.

Mège-Revil, A., Steyer, P., Fontaine, J., Pierson, J.F. \& Esnouf, C. (2009). Oxidation and tribo-oxidation of nanocomposite $\mathrm{Cr}-\mathrm{Si}-\mathrm{N}$ coatings deposited by a hybrid arc/magnetron process. Surf Coat Technol 204, 973-977.

Musil, J., VlceK, J. \& Zeman, P. (2008). Hard amorphous nanocomposite coatings with oxidation resistance above 1000 degrees C. Adv Appl Ceramics 107, 148-154.

Panjan, M., Cekada, M., Panjan, P., Zalar, A. \& Peterman, T. (2008). Sputtering simulation of multilayer coatings in industrial PVD system with three-fold rotation. Vacuum 82, 158-161.

Panjan, M., Peterman, T., Cekada, M. \& Panjan, P. (2009). Simulation of a multilayer structure in coatings prepared by magnetron sputtering. Surf Coat Technol 204, 850-853.

Perez-Omil, J.A. (1994). Interpretacion sistematica de imágenes de microscopía electronica de alta resolucion de materiales policristalino. Estudio de catalizadores metálicos soportados. Eje-Z software programme. Departamento de Ciencia de Materiales e Ingeniería Metalúrgica y Química Inorgánica. Cádiz, Spain: University of Cádiz.

Prescott, R. \& Graham, M.J. (1992). The formation of aluminium-oxide scales on high-temperature alloys. Oxid Met 38, 233-254.

Reiter, A.E., Derflinger, V.H., Hanselmann, B., Bachmann, T. \& SARTORY, B. (2005). Investigation of the properties of $\mathrm{Al}_{1-x} \mathrm{Cr}_{x} \mathrm{~N}$ coatings prepared by cathodic arc evaporation. Surf Coat Technol 7, 2114-2122.

Rojas, T.C., El Mrabet, S., Domínguez-Meister, S., Brizuela, M., García-Luis, A. \& SÁnChez-López, J.C. (2012). Chemical and microstructural characterization of (Y or Zr)-doped CrAlN coatings. Surf Coat Technol 211, 104-110.

Romero-Gomez, P., Palmerom, A., Ben, T., Lozano, J.G., MoLiNA, S.I. \& GonZÁLeZ-Elipe, A.R. (2010). Surface nanostructuring of $\mathrm{TiO}_{2}$ thin films by high energy ion irradiation. Phys Rev B 82, 115420.

Ross, I.M., Rainforth, W.M., Seabourne, C.R., Scott, A.J., Wang, P., Mendis, B.G., Bleloch, A.L., Reinhard, C. \& Hovsepian, P.E.H. (2010). Electron energy loss spectroscopy of nano-scale CrAlYN/CrN-CrAlY $(\mathrm{O}) \mathrm{N} / \mathrm{Cr}(\mathrm{O}) \mathrm{N}$ multilayer coatings deposited by unbalanced magnetron sputtering. Thin Solid Films 518, 5121-5127.

Rovere, F., Mayrhofer, P.H., Reinholdt, A., Mayer, J. \& ScheNEIDER, J.M. (2008). The effect of yttrium incorporation on the 
oxidation resistance of Cr-Al-N coatings. Surf Coat Technol 202, 5870-5875.

Ruck, B.J., Koo, A., Lanke, U.D., Budde, F., Granville, S., Trodahl, H.J., Bittar, A., Metson, J.B., Kennedy, V.J. \& Markwitz, A. (2004). Quantitative study of molecular $\mathrm{N}_{2}$ trapped in disordered GaN:O films. Phys Rev B 70, 235202.

Sánchez, J.E., Sánchez, O.M., Ipaz, L., Aperador, W., Caicedo, J.C., Amaya, C., Hernández Landaverde, M.A., Espinoza Beltrán, F., Muñoz-Saldaña, J. \& Zambrano, G. (2010). Mechanical, tribological, and electrochemical behavior of $\mathrm{Cr}_{1-x} \mathrm{Al}_{x} \mathrm{~N}$ coatings deposited by r.f. reactive magnetron cosputtering method. Appl Surf Sci 256, 2380-2387.

Sánchez-López, J.C., Martínez-Martínez, D., López-Cartes, C., Fernández, A., Brizuela, M., García-Luis, A. \& Oñate, J.I. (2005a). Mechanical behaviour and oxidation resistance of Cr(Al)N coatings. J Vac Sci Technol A 23(4), 681-686.

Sánchez-López, J.C., Martínez-Martínez, D., López-Cartes, C., Fernández-Ramos, C. \& Fernández, A. (2005b). A nanoscale approach for the characterization of amorphous carbonbased lubricant coatings. Surf Coat Technol 200, 40-45.
Steyer, P.H., Mege, A., Pech, D., Mendibide, C., Fontaine, J., Pierson, J.F., Esnouf, C. \& Goudeau, P. (2008). Influence of the nanostructuration of PVD hard TiN-based films on the durability of coated steel. Surf Coat Technol 202, 2268-2277.

Tien, S.-K., Lin, C.-H., Tsai, Y.-Z. \& DuH, J.-G. (2010). Oxidation behavior, microstructure evolution and thermal stability in nanostructured CrN/AlN multilayer hard coatings. J Alloy Comp 489(1), 237-241.

Veprek, S. \& Veprek-Heijman Maritza, J.G. (2008). Industrial applications of superhard nanocomposite coatings. Surf Coat Technol 202(21), 5063-5073.

Wang, L., Nie, X., Housden, J., Spain, E., Jiang, J.C., Meletis, E.I., Leyland, A. \& Matthews, A. (2008). Material transfer phenomena and failure mechanisms of a nanostructured $\mathrm{Cr}$ Al-N coating in laboratory wear test and an industrial punch tool application. Surf Coat Technol 203, 816-821.

Willmann, H., Mayrhofer, P.H., Persson, P.O.A., Reiter, A.E., Hultman, L. \& Mitterer, C. (2006). Thermal stability of Al-Cr-N hard coatings. Scripta Mater 54, 1847-1851. 